\title{
The Role of BIM Technology in Energy-saving Reconstruction of Existing Residential Buildings in Rural Areas
}

\author{
Mingqiang Huanga, Jinheng Li,Chunlin Liao \\ School of Civil Engineering \& Architecture, Xiamen University of Technology, \\ Xiamen, 361024, China.
}

aemail: 2014110905@xmut.edu.cn

Key words: BIM technology, residential buildings in rural areas, energy-saving renovation

Abstract: The energy-saving renovation of existing residential buildings in rural areas is a complex system project. The role of BIM technology in existing residential buildings in rural areas is conducive to the collection of information on the building of existing residential buildings in rural areas. It also help to determine the rationalization of the building structure, and reduce the collision and transformation costs between majors in the transformation process.

\section{Introduction}

The energy-saving construction of residential buildings in rural areas is an important part of the construction of new countryside and the process of promoting urbanization. However, due to multiple factors such as traditional, technical, and economic factors, the energy-saving level of rural areas in China is far behind the current level of the city. At the same time, it also exerts great pressure on the environment and resources, which has become a bottleneck restricting the improvement of the energy-saving level of residential buildings in rural areas. One of the most important reasons is the lack of suitable support for energy-saving technologies in residential buildings in rural areas. In recent years, with the promotion of energy-saving and emission-reduction concepts, many rural areas have conducted energy-saving renovations. However, in the process of reconstruction, the coordination among various specialties such as architecture, structure, and installation has become a difficult problem in transformation. Therefore, on the basis of expounding the challenges of energy saving and emission reduction on the development of construction industry and the meaning of BIM technology, this paper starts from the status quo of energy saving construction of rural areas, and analyzes the role of BIM technology in the energy saving transformation of existing residential buildings in rural areas.

\section{Development of the Construction Industry and BIM Technology}

Accelerate the adjustment of industrial structure, change the mode of economic development, and realize a resource-saving and environment-friendly sustainable development approach. From the blind pursuit of economic development, the process of consuming resources and destroying the environment has turned into a focus on quality and efficiency. As one of the largest energy-consuming industries, the construction industry has also become the key to sustainable development. Therefore, the change in the environment has brought great challenges to the development of the construction industry, and has also brought about new developments in the construction industry. 


\section{The Challenge of Energy Saving and Emission Reduction to the Development of the Construction Industry}

As a big building country, although China has achieved certain results in the industrialization of construction, building materials, and residential industrialization, the low production efficiency in the past, and the problems of backward technology and management, which has led to the consumption of materials in the construction industry is too high in the process of construction and operation. The recycling of construction waste is low, and the pollution of the building environment is severely serious ${ }^{[1]}$.

According to the statistics of the 12th Five-Year Plan for Special Development of Green Building Technologies, as of 2012, the construction waste generated in China due to the development of the construction industry amounts to hundreds of millions of tons per year. And the daily domestic sewage generated by construction activities reaches 5.8 million cubic meters, which cause the pollution accounts for about one-third of all pollution in the country. According to the data shown in the China Statistical Yearbook (2016), China's building energy consumption has increased from 12.13 million tons of standard coal in 1990 to 75.2 million tons of standard coal in 2014, with a growth rate of $519.95 \%$. If comprehensive consideration is given to the production, construction process and operation process of building materials, the growth rate of energy consumption in the construction industry in China will be even faster. Therefore, we will promote the development of green buildings, energy conservation and emission reduction for all citizens, and reduce energy consumption and greenhouse gas emissions in the construction industry. Systematically promote the standardization and greenization of all aspects of the building's entire life cycle, and promotes the application of new technologies, new materials, and new products to green buildings. It is of vital significance to achieve the goal of reducing the carbon dioxide emissions per unit of GDP by 2020 from 40 to $45 \%$ on the basis of 2005 and to improve the country's construction industry's scientific and technological innovation capability.

\section{Buildings will be greener, energy-efficient and environmentally friendly}

The rapid urbanization and socio-economic development have promoted a more harmonious relationship between mankind and nature, and people paid more attention to the use, protection, and treatment of the ecological environment and resources. At the same time, with the improvement of living standards and awareness of energy conservation and environmental protection, people began to retrofit the building of traditional construction methods, and the requirements for improving the comfort of living environment are also more demanding. Therefore, the traditional form of construction will also be transformed into a green, energy-saving, and environmentally-friendly form, which satisfying humans' pursuit of healthy living and good quality of living. The green, energy-saving, environmentally-friendly and livable buildings allow buildings to maximize resources conservation throughout the entire life cycle. It also allow buildings to protect the environment and reduce pollution. Providing humans with healthy and comfortable use of space. As one of the largest consumers of energy, buildings have also received great attention from all over the world in recent energy conservation and emission reduction activities. Therefore, vigorously promoting the construction of green, energy-saving and environmentally-friendly buildings is not only the need for the country to promote sustainable development, but also the strategic direction for China's future development.

\section{Meaning of BIM Technology}

The concept of BIM technology comes along with the in-depth development and application of information technology in the construction industry. The concepts associated with BIM technology 
are also reinterpreted from various perspectives with the different research fields of different experts and scholars. It also derived a lot of terms based on BIM technology, such as integrated building models, virtual building models, and single building models. Therefore, at present, the definition of BIM technology does not have a unified interpretation internationally. The National Academy of Building Research has proposed that the BIM technology is an electronic model of the facility's actions established for a variety of purposes such as visualization, collision analysis, and inspection of specification standards, cost analysis, and completion acceptance. The American Institute of Architects also said that BIM technology is a database-related project and is a model-based project information technology. McGraw-Hill also said that BIM technology is a process of creating and using digital models for the design, construction, and operation management of a project. Tekla's definition of BIM technology is a process of modeling and communication in the structure and details of a building, which is conducive to the management and construction of the entire project life cycle. However, it was unanimously acknowledged that BIM is an abbreviation of the English Building Information or Building Information Model. It is based on the relevant information data of the construction project as the basis of the model, establishes the three-dimensional information model of the construction project, and simulates the real information that the building has through digital information simulation. Therefore, BIM technology is a technique concerning building information modeling and building information modeling. The basic idea is to build a $3 \mathrm{D}$ geometric model based on 2D CAD drawings. The model includes basic building data and supports building standards based on open standards. It provides more powerful technical software for the development and construction of construction projects and improves planning, design, construction management and operation of construction projects. The efficiency and level of maintenance have enabled the sharing of information throughout the entire life cycle of a building and realized the optimization of key aspects such as the entire life cycle cost of the building. At present, BIM technology has become the focus of research and application in the field of construction engineering, and its application value has also been recognized and recognized by the industry and the government.

\section{Status of Energy Saving and Emission Reduction in Villages and Towns}

Energy-saving and emission-reduction of residential houses in villages and towns has always been a key and difficult point for building energy conservation in China. The reason for this is that China's villages and towns have large residential areas and occupy a large amount of cultivated land, and they are basically small houses where residents of villages and towns build their own homes, which are often not designed and consider building energy efficiency. At present, there are mainly the following deficiencies in the buildings of our villages and towns:

\section{The spatial pattern is irrational}

In order to use the existing land as much as possible to build houses with the largest area of use, town and village residents do not usually consider too much about the orientation and spatial layout of houses. Due to the lack of scientific design, village and township residences are often designed by the residents of the rural areas or based on personal preferences. There is no uniform standard. As a result, the overall planning of the villages and towns' homes is chaotic, and residences do not take full account of residential spacing and natural ventilation, resulting in a series of consequences of indoor humidity, poor lighting, and high air conditioning energy consumption.

\section{Poor performance of building materials}

At present, the wall materials used in villages and towns are mainly solid clay bricks. Although 
the country has explicitly prohibited the production and use of solid clay bricks since 1999, it still exists in rural areas ${ }^{[2]}$. Secondly, the doors and windows used in villages and towns' residences are also designed and manufactured by themselves, and their airtightness and heat insulation are relatively poor, which does not achieve the effect of thermal insulation.

\section{Serious environmental pollution}

In the construction of villages and towns, there are not only high energy consumption, but also serious problems of environmental pollution. Due to the lack of reasonable management, the environmental pollution in the construction of villages and towns is serious. The indiscriminate discharge of domestic wastewater has resulted in serious water pollution; the random accumulation of refuse and the lack of proper waste sorting and recovery technologies have caused serious contamination of groundwater, soil and the surrounding environment.

\section{The Role of BIM Technology in Energy Saving Reconstruction of Villages and Towns}

BIM technology has many features such as visual analysis, collision checking, and construction schedule simulation. Through the established BIM model, the solar radiation, sunshine, ventilation, lighting and lighting of buildings can be simulated to discuss the most appropriate orientation, layout, and floor spacing of buildings, as well as to formulate reasonable construction design schemes and select scientific lighting methods, which effectively reduces building energy consumption ${ }^{[3]}$. For the energy-saving renovation of residential houses in towns and villages, the application of BIM technology mainly includes the following aspects:

\section{Make up for the lack of building information}

There are basically no standard design drawings for the construction process of villages and towns. The housing layout is always based on the personal preferences of villages and towns residents. There are no strict inspection standards for the construction materials used, and the lack of relevant building information brings great difficulties to the energy-saving reconstruction of existing villages and towns. Therefore, in the energy-saving reconstruction of existing rural areas, it is necessary to measure the existing rural areas in advance, collect the corresponding building materials, use BIM technology to draw out its three-dimensional visualization model, to guide the later energy-saving transformation and construction simulation analysis.

\section{Determine a Reasonable House Pattern}

In order to maximize the use of land area, the residents of the villages and towns will basically ignore the characteristics of the building spacing and lighting, and build houses with the largest use area on the limited land. This will lead to the problems of poor lighting and ventilation in the villages and towns, which also led to the summer heat in the villages and towns and the cold winter conditions. Therefore, in the case of existing villages and towns, it is necessary to change the pattern and strengthen natural ventilation. BIM technology can be used to establish the transformed landscape and simulate ventilation. In the process of building a new countryside, the village houses that can be built in a centralized manner need to be planned in a unified way. Use BIM technology to build a three-dimensional visualization model, and use the established model to simulate the sunshine, lighting and ventilation of the house in advance so that the villages and towns can be reasonably determined. The orientation between houses and the space between buildings.

\section{Strengthen professional coordination and reduce the cost of renovation}

The energy-saving renovation of existing residential buildings in rural areas involves majors such as architecture, structure, and installation, and the shapes of existing residences is vary, and there is no coordination between the various majors like new building-house. Therefore, in order to 
ensure the coordination and cooperation among various professions, it is necessary to fully negotiate based on the materials collected in advance and the BIM model that has been constructed to simulate the transformation scheme. Virtual components such as residential structures and internal pipelines are presented in front of the transformers in a visual manner, thereby we can reduce the collisions between various professionals in the transformation process and reducing the cost of the renovation.

\section{Conclusion}

Energy-saving and emission-reduction have become a consensus reached all over the world, and existing residential energy-saving renovation has become an important part of energy-saving emission reduction. The energy-saving renovation of residential houses in villages and towns is a complex system project. The use of BIM technology to improve the quality of transformation has become a research hotspot and a difficult point. This article discusses the role of BIM technology in the transformation of existing residential buildings in towns, which lacks practical case studies. Therefore, in future research, the use of real-world cases will be further utilized to explore the significance of BIM technology for energy-saving reconstruction of existing residential buildings in villages and towns.

\section{Acknowledgements}

This research was supported by the National Natural Science Foundation of China (NSFC) (Grant No.71503224) and Fujian Social Natural Science Foundation (Grant No. FJ2015C110). The work described in this paper was also funded by Fujian Province Middle and Young Teacher Education Research Program (Grant No. JA15374) ; the Program for High Level Talents in Xiamen University of Technology (Grant No. YKJ4024R)and University Outstanding Young Scientific Research Talent Cultivation Program Project in Fujian Province

\section{References}

[1] Huang Mingqiang. Analysis of current status and influencing factors of energy-saving construction of residential buildings in villages and towns in China[J] Building Materials and Decoration, 2016(46):139-140.

[2] Wang Peiming. Brief introduction of the development of new building materials in China [J] Foreign Building Materials Technology, 2004 (4): 97-98.

[3]WANG Zhenshuang, WANG Liguo, GAO Ping, CHEN Xiaobo. Research on green building materials management system based on BIM technology[J] Building Economy, 2015(4):83-86. 